DOI: 10.12731/2070-7568-2020-2-7-29

УДК 338.242.2

\title{
СРАВНИТЕЛЬНЫЙ АНАЛИЗ \\ МЕТОДОВ ОЦЕНКИ ВЕРОЯТНОСТИ БАНКРОТСТВА (НА ПРИМЕРЕ ПРЕДПРИЯТИЙ СОТОВОЙ СВЯЗИ РОССИЙСКОЙ ФЕДЕРАЦИИ)
}

\author{
Аксинина О.С., Гасилина О.М.
}

На современном этапе развития российской экономики становится очевидным, что любое предприятие для сохранения финансовой устойчивости и долгосрочной конкурентоспособности должно отвечать требованиям окружающей действительности [13]. Одной из наиболее развивающихся отраслей экономики является рынок связи и телекоммуникаций, что во многом связано с современным трендом-цифровая экономика [1], а в частности, с национальным проектом «Цифровая экономика в Российской Федерации». Потребность в оченке финансового состояния и прогнозирования его изменений испытывает как сам экономический субъект, так и его контрагенты, инвесторы и другие заинтересованные пользователи отчётности. Как следствие, выявление неблагоприятных тенденций развития предприятия, рисковых факторов, приводящих к банкротству и методов их оиенки, приобретают первостепенное значение. Но, несмотря на большое количество различных моделей оченки степени риска банкротства, в современной экономической науке нет единого формализованного подхода, каждая модель опирается на свою группу показателей и нормативных значений. Именно поэтому для получения объективной информации о финансовом состоянии предприятий сотовой связи необходимо использовать модели различных авторов. Помимо этого следует рассмотреть показатели, необходимые для прогнозирования финансовой несостоятельности исследуемых субъектов, а также разработать возможные их модификации, применимые 
непосредственно к телекоммуникационной отрасли. Приведённый порядок действий, безусловно, помогает выявить слабые места в деятельности исследуемых экономических субъектов, а вместе с этим, выяснить, смогут ли крупные участники рынка связи, такие как, как ПАО «Мегафон», ПАО «МТС», ПАО «Ростелеком», стать основополагающими, с помощью которых удастся реализовать нацчиональный проект в Самарской области.

Цель: оченить возможность применения известных методик прогнозирования банкротства и финансовых коэффициентов к крупным телекоммуникационным компаниям Самарского региона.

Метод или методология проведения работы: в статье использовались экономико-математические методы, а также статистические методы анализа.

Результаты: оценена возможность применения представлена известных методик прогнозирования банкротства к телекоммуникационным компаниям региона. Представлена скорректированная формула собственных оборотных средств, которая учитывает отраслевые особенности участников рынка связи, тем самылм показывает их реальное финансовое положение.

Область применения результатов: полученные результаты целесообразно применять экономическим субъектам телекоммуникационной отрасли экономики.

Ключевые слова: банкротство; экономический субъект; модели прогнозирования банкротства; ичифровизация экономики.

\section{COMPARATIVE ANALYSIS OF METHODS FOR ASSESSING THE LIKELIHOOD OF BANKRUPTCY (ON THE EXAMPLE OF CELLULAR COMMUNICATION ENTERPRISES OF THE RUSSIAN FEDERATION)}

\section{Aksinina O.S., Gasilina O.M.}

At the present stage of development of the Russian economy, it becomes obvious that any enterprise in order to maintain financial stability and 
long-term competitiveness must meet the requirements of environmental reality [13]. One of the most developing sectors of the economy is the communications and telecommunications market, which is largely connected with the current trend - the digital economy [1], and in particular, with the national project "Digital Economy in the Russian Federation". The need to assess the financial condition and forecast its changes is experienced by both the economic entity itself and its counterparties, investors and other interested users of reporting. As a consequence, the identification of unfavorable trends in the development of the enterprise, risk factors leading to bankruptcy and methods for their assessment are of paramount importance. But, despite the large number of different models for bankruptcy risk assessment, there is no single formal approach in modern economic science, each model is based on its own group of indicators and normative values. That is why, in order to obtain objective information about the financial condition of cellular communication enterprises, it is necessary to use models of various authors. In addition, it is necessary to consider the indicators needed for predicting the financial insolvency of the studied entities, as well as to develop possible modifications that apply directly to the telecommunications industry. The above procedure, of course, helps to identify weaknesses in the operations of the studied economic entities, and with this, to find out whether large communications market participants, such as PJSC Megafon, PJSC MTS, PJSC Rostelecom, can become fundamental, with the help of which it will be possible to implement the national project in the Samara region.

Purpose: assess ment of the possibility of applying known methods of bankruptcy forecasting and financial ratios to large telecommunication companies of the Samara region.

Methodology in article economic-mathematical methods, and also statistical methods of the analysis were used.

Results: assessed the possibility of applying well known methods bankruptcy forecasting to telecom companies in the region. An adjusted formula of own working capital is presented, which takes into account industry peculiarities of communication market participants, thus showing their real financial situation. 
Practical implications it is expedient to apply the received results the economic subjects of the telecommunications industry.

Keywords: bankruptcy; economic subject; insolvency forecasting models; digitalization of the economy.

\section{Введение}

Одним из наиболее развивающихся сегментов российской экономики является рынок связи и телекоммуникаций. Во многом это связано с национальным проектом «Цифровая экономика Российской Федерации», который начал своё действие в октябре 2018 года. Самарская область по многим показателям занимает лидирующие позиции среди регионов Приволжского федерального округа и характеризуется как регион с высоким уровнем развития информационных технологий и связи [2]. В 2019 году наша область также приступила к реализации национального проекта «Цифровая экономика», который предполагает совершенствование всей системы государственного управления, дальнейшее развитие цифровых технологий и создание цифровой модели региона. Цифровое общество будущего технически невозможно построить, не опираясь на мобильные решения. Передача информации по радиоканалам дает возможность каждому из нас подключиться к единому информпространству, постоянно быть на связи [12]. По этой причине сотовые операторы - активные участники данного национального проекта. Поэтому, считаем целесообразным выяснить, что готовы предложить участники рынка связи и телекоммуникаций для содействия в развитии нового тренда экономики, и смогут ли они инвестировать средства в реализацию проекта, или же сами нуждаются в дополнительных инвестициях в связи с неустойчивым финансовым положением.

На форуме «Цифровая экономика Самарской области - роль телекома» губернатор встретился с представителями филиалов таких крупных компаний, как ПАО «Мегафон», ПАО «МТС», ПАО» Ростелеком» и выслушал их предложения по развитию цифрового общества (таблица 1). 
Таблицуа 1.

Новые возможности цифровизации экономики Самарской области

\begin{tabular}{|c|c|c|}
\hline $\begin{array}{c}\text { Наиме- } \\
\text { нование } \\
\text { участника } \\
\text { рынка } \\
\end{array}$ & Предлагаемые нововведения & $\begin{array}{c}\text { Количество } \\
\text { пользователей }\end{array}$ \\
\hline $\begin{array}{l}\text { ПАО } \\
\text { «Мега- } \\
\text { фон» }\end{array}$ & $\begin{array}{l}\text { • } \text { развитие сетей } 5 \mathrm{G} \text { и интернета вещей (IoT) } \\
\text { • работа с «большими данными» (big data) } \\
\text { ей о своторы сотовой связи обладают информаци- } \\
\text { использование в интересах пользователей, для } \\
\text { этого компания хочет объединить системы обра- } \\
\text { ботки «больших данных» с технологиями IоT. }\end{array}$ & $\begin{array}{l}\text { Пользователи } \\
\text { мобильной свя- } \\
\text { зи - } 45 \% \\
\text { Пользователи } \\
\text { Интернета - } \\
30 \%\end{array}$ \\
\hline $\begin{array}{l}\text { ПАО } \\
« \mathrm{MTC} »\end{array}$ & $\begin{array}{l}\text { • Поиск инновационных решений (в структуре } \\
\text { компании появился центр инвестиций и вен- } \\
\text { чурный фонд) } \\
\text { • Привлечение перспективных компаний-старта- } \\
\text { пов (с } 2017 \text { года было рассмотрено больше ты- } \\
\text { сячи стартапов, около 60\% компаний успешно } \\
\text { развиваются на сегодняшний день во многом, } \\
\text { благодаря инвестиция ПАО «МТС») } \\
\text { • Примером стартапа может служить цифровое } \\
\text { решение для управляющих компаний в сфере } \\
\text { ЖКХ «Умный житель», что войдёт в продукто- } \\
\text { вую линейку вещей от МТС }\end{array}$ & $\begin{array}{l}\text { Пользователи } \\
\text { мобильной свя- } \\
\text { зи - } 45 \% \\
\text { Пользователи } \\
\text { Интернета - } \\
60 \%\end{array}$ \\
\hline $\begin{array}{l}\text { ПАО } \\
\text { «Рос- } \\
\text { телеком» }\end{array}$ & $\begin{array}{l}\text { Закладывается основа для комфортной жизни жите- } \\
\text { лей Самарской области. На оптических сетях связи } \\
\text { можно разворачивать видеоаналитику, телемедици- } \\
\text { ну, дистанционное образование и множество дру- } \\
\text { гих интересных и нужных людям проектов }\end{array}$ & $\begin{array}{l}\text { Пользователи } \\
\text { мобильной свя- } \\
\text { зи - } 10 \% \\
\text { Пользователи } \\
\text { Интернета }-10 \%\end{array}$ \\
\hline
\end{tabular}

Цифровизация - это не только неотъемлемая часть промышленной революции, это огромные возможности для улучшения жизни граждан. Внедрение цифровых технологий позволит на основе большого объёма данных принимать более эффективные и результативные решения, оптимально использовать ресурсы, сделать более удобным получение услуг в сфере медицины, образовании, повысить эффективность госуправления. По оценкам экспертов к 2030 году цифровизация обеспечит рост ВВП России на 19-34\% и рост валового регионального продукта в Самарской области на 62-134 млрд рублей [14].

Как мы видим, новый вектор развития окажет положительное влияние, как на экономику страны, так и на экономическую ситу- 
ацию Самарского региона. Различные аспекты цифровизации рассматривали в своих работах И.Л. Авдеева и В.Г. Варнавский [3]. В них авторы выделяли факторы, затрудняющие развитие данного направления, которые позже нашли своё отражение в национальной программе «Цифровая экономика Российской Федерации». Несмотря на существующие затруднения, в условиях международных санкций, неустойчивости национальной валюты, трансформация как никогда необходима. Так как выделенные факторы негативно сказываются как на макроуровне, так и на уровне отдельно взятого предприятия, считаем целесообразным проанализировать финансовое состояние системообразующих телекоммуникационных организаций, оценить устойчивость их функционирования.

\section{Материалы и методы}

В российской практике прогнозирования банкротства многими специалистами применяются правила, разработанные в соответствии с Федеральным законом «О несостоятельности (банкротстве) от 26.10.2002 №127-Ф3. Данный нормативный документ определил отечественную систему показателей для оценки неплатежеспособности организаций [15].

Понятие «несостоятельность» находит своё отражение в федеральном законе № 127Ф3: признанная арбитражным судом неспособность должника в полном объеме удовлетворить требования кредиторов по денежным обязательствам, о выплате выходных пособий и (или) об оплате труда лиц, работающих или работавших по трудовому договору, и (или) исполнить обязанность по уплате обязательных платежей [16].

Также в настоящее время существуют как западные, так и отечественные методики прогнозирования банкротства предприятий. Зарубежные модели вызывают различные мнения по поводу возможности их применения в России, так как при их разработке не учитывались факторы риска, свойственные российским предприятиям: финансовая обстановка в стране, условия кредитования, особенности налогообложения, темпы инфляции и др. Несмотря 
на это, существует множество различных методик зарубежных авторов, но для исследования были выбраны наиболее популярные и неоднократно описанные в экономической литературе. Среди которых 4-факторная модель Э. Альтмана, модель Р. Таффлера, модель канадского учёного Г. Спрингейта. Их эффективность была доказана на широкой выборке компаний, что также является причиной довольно частого обращения к данным моделям в различного рода исследованиях. Однако, для повышения корректности оценки вероятности наступления банкротства российских организаций необходимо применить также и отечественные методики прогнозирования, предложенные А.Ю. Беликовым, О.П. Зайцевой [19].

Но, несмотря на большое количество различных моделей оценки степени риска банкротства, в современной экономической науке нет единого формализованного подхода, каждый автор опирается на свою группу показателей и нормативных значений.

\section{Результаты и обсуждение}

В таблице 2 представлены показатели, рассчитанные по модели Э. Альтмана.

Таблицуа 2.

\section{Применение модели Э. Альтмана для непроизводственных предприятий} в отношении исследуемых субъектов рынка связи и телекоммуникаций

\begin{tabular}{|c|c|c|c|c|c|c|c|c|c|}
\hline \multirow[t]{3}{*}{$\begin{array}{l}\text { Итоговый коэф- } \\
\text { фициент вероят- } \\
\text { ности банкрот- } \\
\text { ства }\end{array}$} & \multicolumn{9}{|c|}{$\begin{array}{l}\mathrm{Z}=6.56 * \mathrm{X} 1+3.26 * \mathrm{X} 2+6.72 * \mathrm{X} 3+1.05 * \mathrm{X} 4 \\
\text { Если } \mathrm{Z} *>2,6 \text { - зона финансовой устойчивости («зеленая» зона). } \\
\text { Если } 1,1<\mathrm{Z} *<2,6 \text { - зона неопределенности («серая» зона). } \\
\text { Если } \mathrm{Z}^{*}<1,1 \text { - зона финансового риска («красная» зона). } \\
\end{array}$} \\
\hline & \multicolumn{3}{|c|}{ ПАО «Мегафон» } & \multicolumn{3}{|c|}{$\Pi A O « M T C »$} & \multicolumn{3}{|c|}{ ПАО «Ростелеком» } \\
\hline & 31.12 .17 & 31.12 .18 & 30.06 .19 & 31.12 .17 & 31.12 .1 & \begin{tabular}{|l|l|}
8 & 30.06 .19
\end{tabular} & 31.12 .17 & 31.12 .18 & 30.06 .19 \\
\hline $\begin{array}{l}\text { X1 = Оборотный } \\
\text { капитал/Активы }\end{array}$ & 0,157 & 0,152 & 0,101 & 0,180 & 0,167 & 0,150 & 0,115 & 0,137 & 0,148 \\
\hline $\begin{array}{l}X 2=\text { Нераспреде- } \\
\text { ленная прибьль/ } \\
\text { Активы }\end{array}$ & 0,011 & 0,028 & 0,011 & 0,274 & 0,121 & 0,043 & 0,556 & 0,475 & 0,483 \\
\hline $\begin{array}{l}\text { Х3 = Операци- } \\
\text { онная прибыль/ } \\
\text { Активы }\end{array}$ & 0,024 & 0,039 & 0,018 & 0,138 & 0,114 & 0,054 & 0,034 & 0,032 & 0,032 \\
\hline
\end{tabular}


Окончание табл. 2.

\begin{tabular}{|l|l|l|l|l|l|l|l|l|l|}
\hline $\begin{array}{l}\text { X4 = Собствен- } \\
\text { ный капитал/ } \\
\text { Обязательства }\end{array}$ & 0,362 & 0,341 & 0,311 & 1,292 & 0,565 & 0,213 & 0,567 & 0,507 & 0,552 \\
\hline$Z=$ & 2,95 & 1,71 & 1,15 & 4,36 & 2,8 & 1,71 & 3,39 & 3,19 & 3,34 \\
\hline $\begin{array}{l}\text { Cтепень вероят- } \\
\begin{array}{l}\text { ности банкрот- } \\
\text { ства }\end{array}\end{array}$ & $\begin{array}{l}\text { Зеле- } \\
\text { ная } \\
\text { зона }\end{array}$ & $\begin{array}{l}\text { Се- } \\
\text { рая } \\
\text { зона }\end{array}$ & $\begin{array}{l}\text { Се- } \\
\text { рая } \\
\text { зона }\end{array}$ & $\begin{array}{l}\text { Зеле- } \\
\text { ная } \\
\text { зона }\end{array}$ & $\begin{array}{l}\text { Зеле- } \\
\text { ная } \\
\text { зона }\end{array}$ & $\begin{array}{l}\text { Се- } \\
\text { рая } \\
\text { зона }\end{array}$ & \multicolumn{3}{|c|}{ Зелёная зона } \\
\end{tabular}

Исходя из представленных в таблице 2 данных можно сделать вывод, что все исследуемые предприятия находятся в зелёной зоне финансовой устойчивости, однако к 2019 году отмечается отрицательная динамика в таких организациях как ПАО «Мегафон» и ПАО «МТС». Именно поэтому следует продолжить свой анализ с помощью других зарубежных моделей, таких как модель Г.Спрингейта и модель Р. Таффлера (таблица 3).

Таблийа 3.

Применение моделей Г. Спрингейта и Р. Таффлера для исследуемых субъектов рынка связи и телекоммуникаций

\begin{tabular}{|c|c|c|c|c|c|c|c|c|c|c|c|c|c|c|c|c|}
\hline & \multirow{2}{*}{\multicolumn{7}{|c|}{\begin{tabular}{|l|} 
Модель Г. Спрингейта \\
$\mathbf{Z}=\mathbf{1 , 0 3 X 1}+\mathbf{3 , 0 7 X 2}+\mathbf{0 , 6 6 X 3}$ \\
$\mathbf{+ 0 , 4 X 4}$ \\
$\mathrm{Z}<0,862$ вероятность банкрот- \\
ства велика
\end{tabular}}} & \multirow{2}{*}{\multicolumn{9}{|c|}{$\begin{array}{l}\text { Модель Р. Таффлера } \\
Z=0,53 * X 1+0,13 * X 2+0,18 * X 3 \\
+0,16 * X 4 \\
Z<0,2-\text { вероятность банкрот- } \\
\text { ства высокая; } \\
Z>0,3 \text { - вероятность банкрот- } \\
\text { ства малая. } \\
\end{array}$}} \\
\hline $\begin{array}{l}\text { Расчёт ин- } \\
\text { тегрального } \\
\text { показателя }\end{array}$ & & & & & & & & & & & & & & & & \\
\hline $\begin{array}{l}\text { Расчёт } \\
\text { факторов }\end{array}$ & \multicolumn{7}{|c|}{$\begin{array}{l}\text { X1= Оборотный капитал / Ба- } \\
\text { ланс; } \\
\text { X2=ЕВІТ/Баланс; } \\
\text { Х3=ЕВТ/Краткосрочные обяза- } \\
\text { тельства; } \\
\text { Х4=Выручка(нетто) от реали- } \\
\text { зации / Баланс. }\end{array}$} & \multicolumn{9}{|c|}{$\begin{array}{l}\text { Х1 = Прибыль от продаж / Кра- } \\
\text { ткосрочные обязательства } \\
\text { Х2 = Оборотные активы / (Кра- } \\
\text { ткосрочные обязательства+ } \\
\text { Долгосрочные обязательства) } \\
\text { Х3 = Долгосрочные обязатель- } \\
\text { ства / Общая сумма активов } \\
\text { Х4 = Общая сумма активов / } \\
\text { Выручка от продаж }\end{array}$} \\
\hline Компании & \multicolumn{2}{|l|}{\begin{tabular}{|l|} 
ПАО \\
«Мега- \\
фон»
\end{tabular}} & \multicolumn{2}{|c|}{$\begin{array}{l}\text { ПАO } \\
\text { «MTC» }\end{array}$} & \multicolumn{3}{|c|}{$\begin{array}{l}\text { ПАО } \\
\text { «Росте- } \\
\text { леком» }\end{array}$} & \multicolumn{3}{|c|}{$\begin{array}{l}\text { ПАО } \\
\text { «Мега- } \\
\text { фон» }\end{array}$} & \multicolumn{3}{|c|}{\begin{tabular}{|l} 
ПАО \\
«MTC»
\end{tabular}} & \multicolumn{3}{|c|}{\begin{tabular}{|l} 
ПАО \\
«Росте- \\
леком»
\end{tabular}} \\
\hline Период & 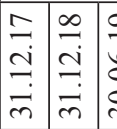 & 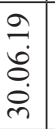 & 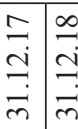 & 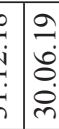 & & 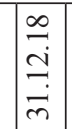 & 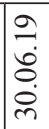 & & & $\frac{9}{8}$ & $m$ & & 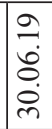 & & & \\
\hline
\end{tabular}


Окончание табл. 3.

\begin{tabular}{|c|c|c|c|c|c|c|c|c|c|c|c|c|c|c|c|c|c|c|}
\hline \multirow{2}{*}{$\begin{array}{l}\text { Степень ве- } \\
\text { роятности } \\
\text { банкротства }\end{array}$} & ○ & $\begin{array}{l}0 \\
\infty \\
\infty \\
\end{array}$ & $\stackrel{\circ}{\infty}$ & ĩ & 5 & 5 & $\begin{array}{l}\circ \\
\circ\end{array}$ & $\begin{array}{l}0 \\
\text { in } \\
\text { D }\end{array}$ & $\begin{array}{l}0 \\
\text { 崩 } \\
\end{array}$ & $\begin{array}{l}0 \\
0 \\
0\end{array}$ & $\begin{array}{l}0 \\
\text { N } \\
\text { N }\end{array}$ & $\begin{array}{l}\circ \\
\pm \\
\pm\end{array}$ & $\begin{array}{l}0 \\
\text { in } \\
0\end{array}$ & $\begin{array}{l}0 \\
\pm \\
\pm\end{array}$ & $\begin{array}{l}0 \\
0 \\
0\end{array}$ & 怘 & $\stackrel{\circ}{\underset{\omega}{\omega}}$ & $\begin{array}{l}0 \\
\stackrel{N}{\infty} \\
\end{array}$ \\
\hline & 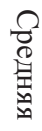 & 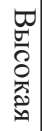 & 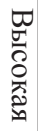 & 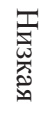 & 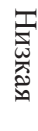 & 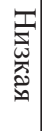 & 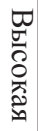 & $\begin{array}{l}\square \\
\sigma \\
\bar{\sigma} \\
0 \\
0 \\
0 \\
0\end{array}$ & 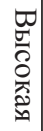 & 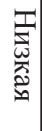 & 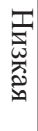 & 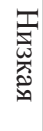 & 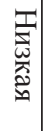 & 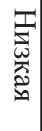 & 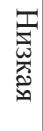 & 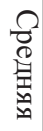 & 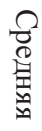 & $E$ \\
\hline
\end{tabular}

Исходя из проведённого анализа с помощью моделей Г. Спрингейта и Р. Таффлера также удалось отметить, что почти у всех объектов исследования финансовое состояние ухудшается и на 2019 год степень вероятности банкротства становится существенной. Однако две зарубежные модели, представленные выше, дали отличные значения о степени риска банкротства таких предприятий как ПАО «Мегафон» и ПАО «Ростелеком». Таким образом, с помощью иностранных моделей не было получено чёткого представления о вероятности банкротства исследуемых организаций. Поэтому считаем целесообразным рассмотреть отечественные модели прогнозирования, которые по замыслу их авторов лишены многих недостатков зарубежных моделей: различия в экономических условиях, системах налогообложения и т.д.; ограниченное количество проанализированных компаний; неактуальность полученной информации для современной российской экономики, отсутствие учёта внешних факторов, в частности санкций к российскому рынку, что актуально на сегодняшний день [6].

Одной из первых российских методик прогнозирования банкротства является модель А.Ю. Беликова, предложенная в 90-х гг.

Таблицуа 4.

Применение модели прогнозирования банкротства А.Ю. Беликова для исследуемых субъектов рынка связи и телекоммуникаций

\begin{tabular}{|c|c|c|c|c|c|c|c|c|c|}
\hline \multirow[t]{3}{*}{$\begin{array}{l}\text { Итоговый } \\
\text { коэффициент } \\
\text { вероятности } \\
\text { банкротства }\end{array}$} & \multicolumn{9}{|c|}{$\begin{array}{l}\mathrm{R}=8,38 * \mathrm{~K} 1+\mathrm{K} 2+0,054 * \mathrm{~K} 3+0,6 * \mathrm{~K} 4 \\
\mathrm{R}<0, \text { максимальная вероятность банкротства } \\
0<\mathrm{R}<0,18, \text { высокая вероятность банкротства } \\
0,18 \leq \mathrm{R}<0,32 \text {, средняя вероятность банкротства } \\
0,32 \leq \mathrm{R}<0,42, \text { низкая вероятность банкротства } \\
\mathrm{R}>0,42 \text { минимальная вероятность банкротства }\end{array}$} \\
\hline & \multicolumn{3}{|c|}{ ПАО «Мегафон» } & \multicolumn{3}{|c|}{ ПАО «MТС» } & \multicolumn{3}{|c|}{ ПАО «Ростелеком» } \\
\hline & 31.12 .17 & 31.12 .18 & 30.06 .19 & 31.12 .17 & 31.12 .18 & 30.06 .19 & 31.12 .17 & 31.12 .18 & 30.06 .19 \\
\hline $\begin{array}{l}\text { K1 = Оборот- } \\
\text { ный капитал/ } \\
\text { Активы }\end{array}$ & 0,157 & 0,152 & 0,101 & 0,18 & 0,167 & 0,15 & 0,115 & 0,137 & 0,148 \\
\hline
\end{tabular}


Окончание табл. 4.

\begin{tabular}{|l|l|l|l|l|l|l|l|l|l|}
\hline $\begin{array}{l}\text { К2=Чистая } \\
\text { прибыль/Соб- } \\
\text { ственный ка- } \\
\text { питал }\end{array}$ & 0.041 & 0.112 & 0.012 & 0.525 & 0,085 & 0,248 & 0,032 & 0,022 & 0,014 \\
\hline $\begin{array}{l}\text { К3 = Выручка/ } \\
\text { Активы }\end{array}$ & 0,614 & 0,525 & 0,114 & 0,538 & 0,392 & 0,202 & 0,5 & 0,508 & 0,241 \\
\hline $\begin{array}{l}\text { К4 Чистая } \\
\text { прибыль/Себе- } \\
\text { стоимость }\end{array}$ & 0.027 & 0,081 & 0,038 & 0.428 & 0,058 & 0,45 & 0,033 & 0,019 & 0,025 \\
\hline $\mathrm{R}=$ & 1,41 & 1,46 & 1,22 & 2,32 & 1,547 & 1,79 & 1,04 & 1,241 & 1,28 \\
\hline $\begin{array}{l}\text { Степень вероят- } \\
\text { ности банкрот- } \\
\text { ства на 2019 и } \\
\text { послед. гг }\end{array}$ & $\begin{array}{l}\text { Яинимальная веро- } \\
\text { ятност банкротства }\end{array}$ & $\begin{array}{l}\text { Минимальная веро- } \\
\text { ятность банкротства }\end{array}$ & $\begin{array}{l}\text { Минимальная веро- } \\
\text { ятность банкротства }\end{array}$ \\
\hline
\end{tabular}

По полученным данным можно сказать, что результаты, полученные по некоторым из анализируемых предприятий, значительно отличаются от итоговых значений, полученных с использованием западных методик. Следовательно, целесообразным будет провести оценку с помощью другой отечественной модели прогнозирования банкротства - модели О.П. Зайцевой.

Таблицуа 5.

\section{Применение модели прогнозирования банкротства О.П. Зайцевой} для исследуемых субъектов рынка связи и телекоммуникаций

\begin{tabular}{|c|c|c|c|c|c|c|c|c|c|}
\hline \multirow[t]{3}{*}{$\begin{array}{l}\text { Итоговый ко- } \\
\text { эффициент } \\
\text { вероятности } \\
\text { банкротства }\end{array}$} & \multicolumn{9}{|c|}{ 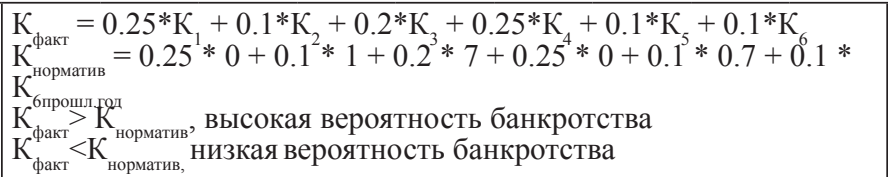 } \\
\hline & \multicolumn{3}{|c|}{ ПАО «Мегафон» } & \multicolumn{3}{|c|}{ ПАО «MТС» } & \multicolumn{3}{|c|}{ ПАО «Ростелеком» } \\
\hline & 31.12 .17 & 31.12 .18 & 30.06 .19 & 31.12 .17 & 31.12 .18 & 30.06 .19 & 31.12 .17 & 31.12 .18 & 30.06 .19 \\
\hline $\begin{array}{l}\text { К1 = При- } \\
\text { быль (убыток) } \\
\text { до налогообл/ } \\
\text { Собственный } \\
\text { капитал }\end{array}$ & 0,0899 & 0,1403 & 0,0154 & 0,6237 & 0,189 & 0,7365 & 0,045 & 0,03 & $-0,01$ \\
\hline $\begin{array}{l}\text { К2= Кредит. } \\
\text { задолжен- } \\
\text { ность/Деби- } \\
\text { торская задол- } \\
\text { женность }\end{array}$ & 1,8748 & 1,8475 & 1,8912 & 1,962 & 1,737 & 2,643 & 1,11 & 1,4 & 1,589 \\
\hline $\begin{array}{l}\text { К3 = Кратко- } \\
\text { срочные обяза- } \\
\text { тельства/ Наи- } \\
\text { более ликвид- } \\
\text { ные активы }\end{array}$ & 5,239 & 3,5772 & 5,634 & 11,642 & 1,38 & 23,81 & 15,546 & 7,52 & 4,689 \\
\hline
\end{tabular}


Окончание табл. 5.

\begin{tabular}{|l|l|l|l|l|l|l|l|l|l|}
\hline $\begin{array}{l}\text { К4 Прибыль } \\
\text { до налогообл/ } \\
\text { Выручка }\end{array}$ & 0,0389 & 0,0675 & 0,0318 & 0,253 & 0,061 & 0,233 & 0,042 & 0,024 & $-0,01$ \\
\hline $\begin{array}{l}\text { К5=Заёмный } \\
\text { капитал/Соб- } \\
\text { ственный ка- } \\
\text { питал }\end{array}$ & 2,7647 & 2,9627 & 3,2989 & 3,573 & 6,864 & 6,299 & 1,131 & 1,435 & 1,777 \\
\hline $\begin{array}{l}\text { К6=Активы/ } \\
\text { Выручка }\end{array}$ & 1,6283 & 1,9057 & 8,7859 & 1,859 & 2,55 & 2,313 & 1,998 & 1,969 & 2,073 \\
\hline R= & 1,71 & 1,59 & 2,54 & 3,106 & 1,583 & 6,13 & 3,355 & 1,801 & 1,268 \\
\hline $\begin{array}{l}\text { Степень ве- } \\
\text { роятности } \\
\text { банкротств }\end{array}$ & $\begin{array}{l}\text { Сред- } \\
\text { няя } \\
(1,8)\end{array}$ & $\begin{array}{l}\text { Сред- } \\
\text { няя } \\
(1.76)\end{array}$ & $\begin{array}{l}\text { Высо- } \\
\text { кая } \\
(2,449)\end{array}$ & $\begin{array}{l}\text { Высо- } \\
\text { кая } \\
(1,75)\end{array}$ & $\begin{array}{l}\text { Низкая } \\
(1.825)\end{array}$ & $\begin{array}{l}\text { Высо- } \\
\text { кая } \\
(1,8)\end{array}$ & $\begin{array}{l}\text { Высо- } \\
\text { кая } \\
(2,03)\end{array}$ & $\begin{array}{l}\text { Средняя } \\
(1,9)\end{array}$ & $\begin{array}{l}\text { Низкая } \\
(1,75)\end{array}$ \\
\hline
\end{tabular}

Результаты, полученные с использованием данной модели, во многом расходятся с уже полученными значениями в модели А.Ю. Беликова. Однако, данная методика подтверждает отрицательную динамику финансового состояния организаций за анализируемый период.

Сопоставив результаты, полученные с помощью различных зарубежных моделей и методик отечественных авторов, можно заметить, что совпадение итоговых значений минимально (таблица 6). Можно согласиться с вышеупомянутым мнением, что большинство иностранных моделей прогнозирования банкротства не учитывают отраслевые особенности российской экономики [17].

В силу этого очень трудно использовать значения коэффициентов в отечественных условиях. Однако сами зарубежные методики прогнозирования с числовыми значениями, которые соответствовали бы российскому рынку, можно было применять, если бы отечественный учёт и отчетность всегда обеспечивали достаточно представительную и достоверную информацию о состоянии предприятия [10].

Также, отсутствие в России статистических материалов по таким организациям не даёт возможность скорректировать методику исчисления весовых коэффициентов и нормативных значений, применимых для российской экономики [22]. 
Таблицуа 6.

Сравнительная таблица коэффициентов различных моделей банкротства

\begin{tabular}{|c|c|c|c|c|c|}
\hline Автор & $\begin{array}{c}\text { Модель } \\
\text { Альтмана }\end{array}$ & $\begin{array}{c}\text { Модель } \\
\text { Срингейта }\end{array}$ & $\begin{array}{c}\text { Модель } \\
\text { Таффлера }\end{array}$ & $\begin{array}{c}\text { Модель } \\
\text { Беликова }\end{array}$ & $\begin{array}{c}\text { Модель } \\
\text { Зайцевой }\end{array}$ \\
\hline $\mathrm{X} 1$ & $\begin{array}{c}+ \\
(6.56)\end{array}$ & $\begin{array}{c}\checkmark \\
(1.03)\end{array}$ & & $\begin{array}{c}+ \\
(8.38)\end{array}$ & \\
\hline $\mathrm{X} 2$ & & & & $\mathbf{R}_{\text {ск }}$ & \\
\hline $\mathrm{X} 3$ & & & $\begin{array}{c}* \\
(0.05)\end{array}$ & \\
\hline $\mathrm{X} 4$ & & & $*$ & & \\
\hline $\mathrm{X} 5$ & & & & & $* 16)$ \\
\hline
\end{tabular}

Из вышеприведённой таблицы 5 видно, что отечественные модели прогнозирования банкротства используют, как минимум, один коэффициент из зарубежной практики. Однако методика Беликова дополнена показателем, не упомянутым в сравнительных моделях: показатель рентабельности собственного капитала. В модели Зайцевой также присутствуют коэффиценты, которые не были учтены в практике зарубежных авторов. Основным достоинством представленных российских методик служит то, что при их разработке использовалась статистика отечественных предприятий, что дает возможность судить о наибольшей точности прогнозируемых данных [18]. Эти факторы повлияли на значительные отклонения в прогнозных значениях, полученных с помощью российских и западных методик прогнозирования. Впрочем, как отмечалось выше, отечественная практика прогнозирования банкротства также не даёт однозначных результатов, расчёты по модели Беликова слабо приближены к итоговым значениям, полученным с использованием методики Зайцевой. С помощью сравнения результатов можно лишь отметить общую тенденцию к ухудшению финансового состояния исследуемых организаций. Следует отметить, что модель Беликова построена на выборке торговых предприятий, в то время как модель Зайцевой разрабатывалась на основе динамики финансовой деятельности производственных организаций. Можно предположить, 
что отраслевая специфика оказывает существенное влияние на деятельность компаний. В связи с чем, рекомендуется учитывать это, как при расчёте нормативных значений коэффициентов, так и значений самих показателей, полученных при помощи различных моделей.

Многие зарубежные и отечественные авторы очень подробно рассматривали вопросы, связанные с банкротством предприятий, а также с возможностью влияния отраслевой специфики на прогнозирование несостоятельности экономических субъектов [5].

Таблицуа 7.

Сравнительная характеристика моделей прогнозирования банкротства

\begin{tabular}{|c|c|c|}
\hline $\begin{array}{c}\text { Название } \\
\text { модели }\end{array}$ & Достоинства модели & Недостатки модели \\
\hline $\begin{array}{l}\text { Модель } \\
\text { Д. Аргенти }\end{array}$ & $\begin{array}{l}\text { Учитывает нефинансовые } \\
\text { факторы и риски; учитыва- } \\
\text { ет качественные показате- } \\
\text { ли; простота расчёта и ин- } \\
\text { терпретации }\end{array}$ & $\begin{array}{l}\text { Неактуальность данных для рос- } \\
\text { сийской экономики (основана на } \\
\text { анализе итальянских предприятий); } \\
\text { отсутствие статистической базы; } \\
\text { субъективность балльной оценки }\end{array}$ \\
\hline $\begin{array}{l}\text { Модель } \\
\text { В.В. Кова- } \\
\text { лёва }\end{array}$ & $\begin{array}{l}\text { Учитывает отраслевую } \\
\text { специфику при определе- } \\
\text { нии нормативных значений; } \\
\text { адаптирована к российской } \\
\text { экономике; учитывает каче- } \\
\text { ственные показатели }\end{array}$ & $\begin{array}{l}\text { Не учитывает макроэкономиче- } \\
\text { ские факторы }\end{array}$ \\
\hline $\begin{array}{l}\text { Модель Ка- } \\
\text { занского го- } \\
\text { сударствен- } \\
\text { ного техно- } \\
\text { логического } \\
\text { университета } \\
\end{array}$ & $\begin{array}{l}\text { Учитывает отраслевую } \\
\text { специфику; адаптирована } \\
\text { под деятельность отече- } \\
\text { ственных предприятий }\end{array}$ & $\begin{array}{l}\text { Нормативы опираются на средне- } \\
\text { отраслевые значения показателей, } \\
\text { что не является стабильной базой }\end{array}$ \\
\hline $\begin{array}{l}\text { Модель } \\
\text { Г.А. Хайдар- } \\
\text { шиной }\end{array}$ & $\begin{array}{l}\text { Учитывает отраслевую } \\
\text { принадлежность организа- } \\
\text { ций; адаптирована под де- } \\
\text { ятельность отечественных } \\
\text { предприятий; учитывает } \\
\text { качественные показатели } \\
\end{array}$ & $\begin{array}{l}\text { Слишком большое число } \\
\text { факторов,что делает расчёт более } \\
\text { трудоёмким, некоторые показатели } \\
\text { схожи между собой; использование } \\
\text { непубличных факторов, доступ к } \\
\text { которым может быть затруднён } \\
\end{array}$ \\
\hline $\begin{array}{l}\text { Модель } \\
\text { О.О. Тере- } \\
\text { щенко }\end{array}$ & $\begin{array}{l}\text { Адаптирована под деятель- } \\
\text { ность отечественных пред- } \\
\text { приятий; учитывает отрас- } \\
\text { левые особенности; есть } \\
\text { возможность модификации } \\
\text { модели для предприятий } \\
\text { разного рода деятельности }\end{array}$ & $\begin{array}{l}\text { Сложность расчёта итогового по- } \\
\text { казателя; }\end{array}$ \\
\hline
\end{tabular}


Таким образом, модели, учитывающие отраслевую специфику предприятия, также не лишены недостатков. Мы считаем, что для получения наиболее точного результата о финансовом состоянии того или иного экономического субъекта, следует использовать ряд различных моделей прогнозирования несостоятельности, так как на сегодняшний день методика универсального типа не разработана.

Конечно, получение прогноза будущего состояния экономического субъекта, возможности наступления (ненаступления) банкротства является основной целью исследования, но для руководителя предприятия это цель промежуточная, ведь для него важнее не спрогнозировать возможные негативные события, а избежать их и обеспечить устойчивое развитие.

Специальные аналитические процедуры помогают оценить влияние внутренних и внешних факторов на финансовую устойчивость предприятия, а также выявить события, которые сигнализируют об угрозе банкротства [8]. Примерами таких событий являются: снижение продаж, частые потери от существенных сделок, нехватка оборотных средств, отрицательная разница от притока и оттока денежных средств, отказ поставщиков в кредите, рост сомнительной дебиторской задолженности и др. Применение анализа позволяет выявить и оценить последствия негативных факторов, дать оценку их влияния на финансовые показатели деятельности [7].

На основании проведённого исследования минимальная вероятность банкротства присуща ПАО «МТС» и ПАО «Ростелеком», финансовое состояние ПАО «Мегафон» находится на среднем уровне. В целях повышения качества управленческих решений в области финансово-экономической деятельности особое внимание следует уделить методам, используемым для расчёта показателей финансовой устойчивости экономического субъекта, а также аналитическим приёмам [21]. Исследуемые организации - участники рынка связи телекоммуникаций, отраслевая специфика их деятельности напрямую влияет на структуру бухгалтерского баланса(величина внеоборотных активов, в большинстве случаев, превышает размер собственного капитала), следствием чего становится отрицательная величина соб- 
ственных оборотных средств. Такие авторы как В.В. Ковалёв, Г.А. Хайдаршина, О.О. Терещенко [9] обращались к вопросам влияния отраслевой специфики на деятельность компаний, в связи с этим корректировались нормативные значения, а также итоговые значения для разного рода организаций. Как методики прогнозирования не являются универсальными, так и финансовые показатели. Возможно, для эффективного анализа текущего состояния исследуемых предприятий необходима модификация существующих формул, что рассматривают в своём исследовании Александрова и Проскурина [4]. Исследуя отчётность трёх телекоммуникационных компаний, с использованием классической формулы финансового анализа, можно заметить, что она демонстрируют отрицательное значение основополагающего показателя, хотя в действительности эти предприятия развиваются, как минимум 2 из 3 имеют достаточно устойчивое финансовой положение. Следовательно, общепринятая формула расчёта собственных оборотных средств, не отражает действительное финансовое положение участников рынка связи и телекоммуникаций [20].

Собственные оборотные средства $(\mathrm{COC})=$ Собственный капитал(СК) - Внеоборотные активы(ВА)

$$
\text { Коб. }=\frac{\text { СОС }}{\text { Оборотные активы }}
$$

Например, в ПАО «Ростелеком» на 30.06.2019 г. величина СОС, рассчитанная по классической формуле, принимает отрицательное значение (-276882,3 тыс. руб.), в ПАО «МТС» (-586094978 тыс. руб.), в ПАО «Мегафон» (-424668049 тыс.руб.) что свидетельствует об отсутствии у организации собственных оборотных средств признак финансовой неустойчивости. Таким образом, дефицит денежных средств, необходимых для финансирования внеоборотных активов испытывают все три исследумых предприятия, несмотря на это, ПАО «МТС» и ПАО «Ростелеком» успешно развиваются и являются финансово устойчивыми компаниями.

В связи с возникшими противоречиями в определении величины $\mathrm{COC}$, мы предлагаем модифицированную формулу расчёта данного 
индикатора. Телекоммуникационные компании для финансирования внеоборотных активов, в большей степени, используют краткосрочные и долгосрочные кредиты и займы, а также обращаются к долгосрочным оценочным обязательствам [11]. С помощью внесённых корректировок формула примет вид:

$$
\mathrm{COC}_{\text {мод. }=} \mathrm{CК}+\text { ККиЗ+ДКиЗ+ОО }+ \text { КЗ- ВА, }
$$

где ККиЗ - краткосрочные кредиты и займы; ДКиЗ - долгосрочные кредиты и займы; ОО - оценочные обязательства; КЗ - кредиторская задолженность в части поставщиков и подрядчиков

Однако необходимо учитывать, что использование краткосрочных заёмных средств, с целью финансирования текущей деятельности возможно только в том случае, если операционный цикл компании превышает срок использования краткосрочных заёмных средств [21].

Проведём повторный расчёт собственных оборотных средств ООО «Ростелеком» только с помощью модифицированной формулы

$\mathrm{COC}_{30.06 .2019}=244736600+36094775+194393546+12926420+$ $+73886277-521618859=+24409144$

$\mathrm{K}_{\text {об. }}=24409144 / 94980991=0,26$

Для ПАО «Мегафон»:

$\mathrm{COC}_{30.06 .2019}=153860616+38773356+358290379+3993694+$ $+47626175-578528665=+24015555$

$\mathrm{K}_{\text {об. }}=24015555 / 70882917=0,34$

Для ПАО « МТС»:

$\mathrm{COC}_{30.06 .2019}=127967078-+145484473+313520476+5964731+$ $+48742085-714062056=-69463795$

$\mathrm{K}_{\text {об. }}=-69463795 / 83440171=-0,83$

Скорректированная формула учитывает отраслевые особенности данных организаций, тем самым показывает реальное финансовое положение исследуемых компаний.

Представленная модификация формулы собственных оборотных средств является научно обоснованной и объективной. Несмотря на это экономическим субъектам данной отрасли необходимо увеличивать собственный капитал, ведь именно он должен быть базой для финансирования текущей деятельности, так как не генерирует получение прибыли. 
На наш взгляд не менее эффективным является проведение предварительного диагностического анализа, который включает в себя несколько групп показателей для определения признаков и угроз финансовой несостоятельности предприятия

1. Группа абсолютных показателей

2. Группа показателей ликвидности и платёжеспособности

3. Группа показателей финансовой устойчивости

4. Группа показателей оборачиваемости дебиторской и кредиторской задолженности

5. Группа показателей рентабельности

Данные показатели также направлены на расчёт вероятности возникновения банкротства исследуемой организации [24].

\section{Заключение}

Таким образом, результаты расчёта рассмотренных моделей прогнозирования банкротства позволили установить отрицательную динамику финансового состояния исследуемых экономических субъектов, что является основанием для принятия своевременных управленческих решений во избежание наступления их несостоятельности. Наше исследование подтверждает мнение о том, что на сегодняшний день универсальной методики прогнозирования банкротства не существует. Каждая из рассмотренных моделей как зарубежная, так и отечественная не лишена недостатков, что и является причиной получения противоречивых выводов о финансовом состоянии той или иной компании. Именно поэтому для получения наиболее точного результата о финансовом состоянии следует использовать ряд различных моделей прогнозирования, учитывающих нефинансовые факторы, отраслевую специфику предприятий. Как методики не являются универсальными, так и финансовые показатели. Представленная в исследовании модификация формулы собственных оборотных средств адаптирована под деятельность компаний телекоммуникационной отрасли, специфику которой рассматривала в своей работе Н.А. Казакова. Несмотря на то, что нехватка собственного капитала наблюдается у всех трёх участников рынка связи, все они являются успешно функционирующими компаниями. 
Прогнозирование финансовой несостоятельности на основании моделей оценки финансового состояния, разработка различных модификаций формул (показателей), применимых к телекоммуникационной отрасли, безусловно, помогают выявить слабые места в деятельности исследуемых экономических субъектов. Однако, не стоит забывать о том, что успешное развитие отрасли требует не только инноваций, но и инвестиций [23]. На наш взгляд, государство - один из важных инвесторов и регуляторов деятельности телекоммуникационной отрасли. В российской Федерации участников данной сферы деятельности контролируют несколько государственных структур, которые руководствуются Федеральным законом «О связи» от 07.07.2003 № 126-Ф3: министерство информационных технологий и связи РФ, федеральная служба по надзору в сфере связи, федеральное агентство по информационным технологиям, федеральное агентство связи, региональные структуры управления. В 2018 году инвестиции в деятельность телекоммуникаций составили 447,5 млрд.руб, что на 3,4\% больше, чем в 2015 году. В связи со стартом национального проекта «Цифровая экономика Российской Федерации» можно предположить, что инвестиции в телекоммуникационную отрасль будут только расти. Следовательно, не менее важным является проведение инвестиционного анализа, для рассмотрения эффективности вложений, отдачи инвестиций и др. Именно поэтому, исследование следует продолжить уже в разрезе инвестиций, вложенных в отрасль телекоммуникаций и связи, а в частности, в исследуемые организации.

\section{Список литературы}

1. Атурин В.В., Мога И.С., Смагулова С.М. Управление цифровой трансформацией: научные подходы и экономическая политика // Управленец. 2020. Т.11, №2, С. 67-76. DOI: 10.29141/2218-5003-2020-11-2-6.

2. Анорбоев А.У., Бондаренко В.В., Галиуллин А.А. и др. Теоретико-методологические подходы к формированию системы развития предприятий, комплексов, регионов: монография / Под. общ. ред. Удалова Ф.Е., Бондаренко В.В., Столяровой О.А. Пенза: РИО ПГАУ, 2019. 233 с. 
3. Авдеева И.Л. Анализ перспектив развития цифровой экономики в России и за рубежом // Цифровая экономика и «Индустрия 4.0»: проблемы и перспективы. 2017. C. 18-24, DOI: 10.18720/ IEP/2017.1/1

4. Александрова М.В., Проскурина З.Б. Особенности применения различных методик для предупреждения банкротства отечественных предприятий // Экономика, социология и право. 2015. № 3.

5. Бобылева А.З. Модернизация института банкротства как ключевой фактор повышения эффективности рыночной экономики // Вестник Московского университета. Сер. 21. Управление (государство и общество). 2019. № 3. С. 39-60.

6. Брянцева Т.А., Глазырина А.А. Проблема прогнозирования банкротства российских предприятий // Белгородский экономический вестник. 2019. №1. С. 173-175.

7. Бланк И.А. Основы финансового менеджмента. / Ника - Центр, Эльга, Киев, 2017.

8. Грязнова А.Г. Антикризисный менеджмент. / Ассоциация авторов и издателей «Танде». Изд-во ЭКМОС, 2017. 360 с.

9. Захарян А.В., Бойко А.А., Сафарова С.Н. Практика использования различных зарубежных методик прогнозирования банкротства организаций // Международный журнал гуманитарных и естественных наук. 2020. №4. DOI: 10.24411/2500-1000-2020-10324.

10. Казакова Н.А. Диагностика и прогнозирование банкротства// Финансовый менеджмент. 2016. № 6. С. 17-33.

11. Казакова Н.А. Риск-ориентированная модель оценки вероятности банкротства компаний, входящих в стратегические альянсы // Экономический анализ: теория и практика. 2019. Т. 18, № 07.

12. Национальная программа «Цифровая экономика Российской Федерации»/ Правительство России. http:/government.ru/rugovclassifier/614/ events/

13. Наумова О.А., Тюгин М.А. Система комплаенс-контроля в обеспечении финансовой безопасности // Европейские труды по социальным и поведенческим наукам. 2018. Вып. 57: GCPMED 2018 / Международная научная конференция «Глобальные вызовы и перспективы 
современного экономического развития». С. 1032-1041. DOI: https:// dx.doi.org/10.15405/epsbs. 2019.03.103.

14. Россия в цифрах. 2018: крат. стат. сб. / Федеральная служба государственной статистики (Росстат). М., 2018.

15. Федеральный закон «О несостоятельности (банкротстве)» от 26.10.02 N127-Ф3 [электронный ресурс]. URL: http://www.consultant.ru

16. Федеральный закон «О бухгалтерском учёте» от 06.12.11 «402-ФЗ» [электронный ресурc]. URL: http://www.consultant.ru

17.Цуркан M.В., Соцкова С.И., Любарская М.А. Влияние партисипативного бюджетирования на инфраструктурное развитие территорий Российской Федерации // Международный журнал экологического и научного образования. 2016. Т. 11. № 15. С. 7684-7702.

18. Шеремет А.Д. Методика финансового анализа деятельности коммерческих организаций / А.Д. Шеремет, Е.В. Негашев. М.: ИНФРА-М, 2017. 233 c. С. 205-219.

19. Drotar P., Gnip P., Zori M., Gazda V. (2019) Data in Brief, 25. DOI: 10.1016/j.dib.2019.104360. Accessed: 29.07.2019.

20 Chena Z., Chena W., Shibcde Y. (2020) Ensemble learning with label proportions for bankruptcy prediction. Expert Systems with Applications, 146. DOI: 10.1016/j.eswa.2019.113155. Accessed: 15.05.2020.

21. Feng M., Shaonan T., Chihoon L., Ling M. (2019) Deep learning models for bankruptcy prediction using textual disclosures. European Journal of Operational Research, 274 (2):743-758. DOI: 10.1016/j.ejor.2018.10.024.

22.Le T., Vo B., Fujita H., Nguyen N., Baik S. (2019) A fast and accurate approach for bankruptcy forecasting using squared logistics loss with GPU-based extreme gradient boosting. Information Sciences, 494: 294 310. DOI: 10.1016/j.ins.2019.04.060.

23. Tobback E., Bellotti T., Moeyersoms J., Stankova M., Martens D. (2017) Bankruptcy prediction for SMEs using relational data. Decision Support Systems, 102: 69-81. DOI: 10.1016/j.dss.2017.07.004.

24.Zoričák M., Gnip P., Drotár P., Gazda V. (2020) Bankruptcy prediction for small- and medium-sized companies using severely imbalanced datasets. Economic Modelling, 84: 165-176. DOI: 10.1016/j. econmod.2019.04.003. 


\section{References}

1. Aturin V.V., Moga I.S., Smagulova S.M. Upravlenets. 2020. V.11, №2, pp. 67-76. DOI: 10.29141/2218-5003-2020-11-2-6

2. Anorboev A.U., Bondarenko V.V., Galiullin A.A. et al. Teoretiko-metodologicheskie podkhody $k$ formirovaniyu sistemy razvitiya predpriyatiy, kompleksov, regionov [Theoretical and methodological approaches to the formation of the system of development of enterprises, complexes, regions] / Ed. Udalov F.E., Bondarenko V.V., Stolyarova O.A. Penza: RIO PGAU, 2019. 233 p.

3. Avdeeva I.L. Tsifrovaya ekonomika $i$ «Industriya 4.0»: problemy i perspektivy [Digital economy and Industry 4.0: problems and prospects]. 2017. P. 18-24, DOI: 10.18720/IEP/2017.1/1

4. Aleksandrova M.V., Proskurina Z.B. Ekonomika, sotsiologiya i pravo. 2015. № 3.

5. Bobyleva A.Z. Vestnik Moskovskogo universiteta. Ser. 21. Upravlenie (gosudarstvo i obshchestvo). 2019. № 3, pp. 39-60.

6. Bryantseva T.A., Glazyrina A.A. Belgorodskiy ekonomicheskiy vestnik. 2019. №1, pp. 173-175.

7. Blank I.A. Osnovy finansovogo menedzhmenta [Fundamentals of Financial Management]. Nika-Tsentr, El'ga, Kiev, 2017.

8. Gryaznova A.G. Antikrizisnyy menedzhment [Anti-crisis management]. Assotsiatsiya avtorov i izdateley «Tande». Izd-vo EKMOS, 2017. $360 \mathrm{p}$.

9. Zakharyan A.V., Boyko A.A., Safarova S.N. Mezhdunarodnyy zhurnal gumanitarnykh i estestvennykh nauk. 2020. №4. DOI: 10.24411/25001000-2020-10324.

10. Kazakova N.A. Finansovyy menedzhment. 2016. № 6, pp. 17-33.

11. Kazakova N.A. Ekonomicheskiy analiz: teoriya i praktika. 2019. V. 18, № 07.

12. Natsional'naya programma «Tsifrovaya ekonomika Rossiyskoy Federatsii»/Pravitel'stvo Rossii [National program "Digital economy of the Russian Federation"]. http:/government.ru/rugovclassifier/614/events/

13. Naumova O.A., Tyugin M.A. Evropeyskie trudy po sotsial'nym i povedencheskim naukam. 2018. Vyp. 57: GCPMED 2018/Mezhdunarodnaya 
nauchnaya konferentsiya "Global'nye vyzovy i perspektivy sovremennogo ekonomicheskogo razvitiya" [European works on social and behavioral sciences. 2018. Issue. 57: GCPMED 2018 / International Scientific Conference "Global Challenges and Prospects for Contemporary Economic Development"]. P. 1032-1041. DOI: https://dx.doi.org/10.15405/ epsbs. 2019.03.103.

14. Rossiya $v$ tsifrakh [Russia in numbers]. 2018: krat. stat. sb. / Federal'naya sluzhba gosudarstvennoy statistiki (Rosstat). M., 2018.

15. Federal'nyy zakon "O nesostoyatel'nosti (bankrotstve)》 ot 26.10.02 N127-FZ [Federal law "On insolvency (bankruptcy)" from 26.10.02 N127-FZ]. URL: http://www.consultant.ru

16.Federal'nyy zakon «O bukhgalterskom uchete» ot 06.12.11 «402-FZ [Federal law “On accounting” from 06.12.11 402-FZ]. URL: http://www. consultant.ru

17. Tsurkan M.V., Sotskova S.I., Lyubarskaya M.A. Mezhdunarodnyy zhurnal ekologicheskogo i nauchnogo obrazovaniya. 2016. V. 11. № 15, pp. 7684-7702.

18. Sheremet A.D., Negashev E.V. Metodika finansovogo analiza deyatel'nosti kommercheskikh organizatsiy [Methodology of financial analysis of the activity of commercial organizations]. M.: INFRA-M, 2017. 233 p., pp. 205-219.

19. Drotar P., Gnip P., Zori M., Gazda V. (2019) Data in Brief, 25. DOI: 10.1016/j.dib.2019.104360. Accessed: 29.07.2019.

20. Chena Z., Chena W., Shibcde Y. (2020) Ensemble learning with label proportions for bankruptcy prediction. Expert Systems with Applications, 146. DOI: 10.1016/j.eswa.2019.113155. Accessed: 15.05.2020.

21.Feng M., Shaonan T., Chihoon L., Ling M. (2019) Deep learning models for bankruptcy prediction using textual disclosures. European Journal of Operational Research, 274 (2):743-758. DOI: 10.1016/j. ejor.2018.10.024

22.Le T., Vo B., Fujita H., Nguyen N., Baik S. (2019) A fast and accurate approach for bankruptcy forecasting using squared logistics loss with GPU-based extreme gradient boosting. Information Sciences, 494: 294 310. DOI: 10.1016/j.ins.2019.04.060. 
23. Tobback E., Bellotti T., Moeyersoms J., Stankova M., Martens D. (2017) Bankruptcy prediction for SMEs using relational data. Decision Support Systems, 102: 69-81. DOI: 10.1016/j.dss.2017.07.004.

24.Zoričák M., Gnip P., Drotár P., Gazda V. (2020) Bankruptcy prediction for small- and medium-sized companies using severely imbalanced datasets. Economic Modelling, 84: 165-176. DOI: 10.1016/j. econmod.2019.04.003.

\section{ДАННЫЕ ОБ АВТОРАХ}

Аксинина Ольга Сергеевна, кандидат экономических наук, доцент кафедры «Учет, анализ и экономическая безопасность» ФГБОУ ВО «Самарский государственный экономический университет»

ул. Советской Армии, 141, г. Самара, 443090, Российская Федерачия

mystep2009@yandex.ru

Гасилина Ольга Михайловна, студент

ФГБОУ ВО «Самарский государственный экономический университет»

ул. Советской Армии, 141, г. Самара, 443090, Российская Федерачия

olyagasilina@mail.ru

\section{DATA ABOUT THE AUTHORS}

Aksinina Olga Sergeevna, Candidate of Economic Sciences, Docent of the Department «Accounting, Analysis and Economic Security» Samara State University of Economics

141, Soviet Army str., Samara, 443090, Russian Federation mystep2009@yandex.ru

Gasilina Ol'ga Mikhaylovna, student

Samara State University of Economics

141, Soviet Army str., Samara, 443090, Russian Federation olyagasilina@mail.ru 